\title{
Guidelines for the Motivational Design of Instructional Simulations
}

\author{
Don G. Robison, Old Dominion University \\ Ginger S. Watson, Old Dominion University
}

\begin{abstract}
Learner motivation is fundamental to effective learning. This article addresses the challenges and opportunities of motivational design for instructional simulations and presents motivational design guidelines. The types and uses of instructional simulations are defined. The elements of motivation as they are described in various models and theories are surveyed. Models and theories considered include the ARCS motivation model, the intrinsic motivation model, selfdetermination theory, motivation systems theory, arousal theory and flow. The unique motivational challenges and opportunities of instructional simulations are analyzed, and then guidelines for the effective motivational design of instructional simulations are offered.
\end{abstract}

Keywords: Simulation, learning, design methodology, motivation, instructional simulation, learner motivation, visual design, aesthetic, social learning, Malone, ARCS Motivation Model

The research about effective learning resonates with this truth: in order for learners to process energetically and learn deeply, they must choose to engage (Blumenfield, Kempler, \& Krajcik, 2006; Jonassen, 1988; Keller \& Suzuki, 1988). Learning is an act: It requires the learner's energy, choice, and employment of effective learning strategies. Because learning is an act-something a learner must do-motivation is fundamental. Some instructional and simulation designers avoid serious attempts to incorporate motivational design in their instructional products because of perceptions that motivation is either too vague a concept (Weiner, 1992) or lacks predictive power in respect to learning outcomes (Gagné, 1965). It is true that motivation is complex, but it is so foundational to learning that it must be thoughtfully addressed in instructional design. This article examines the unique motivational challenges and opportunities of instructional simulations and provides guidelines for their motivational design. First, let us define two key terms: instructional simulation and motivation.
What is motivation? Motivation is about why people do what they do. Simply defined, it is what people desire to do, choose to do, and commit to do (Keller, 2009). It is an internal process, but can be inferred from observed choices, effort, intensity, and persistence. It is what initiates behavior, controls its intensity, maintains behavior, stops behavior, and mediates choice (Weiner, 1992). The study of motivation should also be focused on how goal-oriented activity is initiated and sustained (Ford, 1992; Schunk, Pintrich, \& Meece, 2002). As previously mentioned, motivation is sometimes considered a vague concept. It is helpful to recall that the word "motivate" is a derivative of the Latin word, movere, which simply means "to move" (The Latin Dictionary, 2013). Motivation, then, in its broadest sense, is about what makes people move.

Learner motivation is focused on those factors that affect a learner's engagement with the task of learning. It can be thought of in two ways: as either stimulating and empowering a learner's intrinsic motivation; or, as providing extrinsic motivators that 
will energize learner engagement. In reality, motivation is the product of a system of influences that are both internal to the learner and external in the learning environment.

This article addresses the motivational challenges of instructional simulation and provides guidelines for their motivational design. Motivation as it applies to simulation will be addressed from several vantage points. Rather than provide a detailed description of each relevant motivation model, the elements of motivation as they are described by a broad crosssection of the literature will be presented. The theoretical or research origins and a brief description of each element will be offered. In this way, the scope of the issue and the pertinent theoretical constructs will emerge. This article is divided into four sections. First, the types of instructional simulations will be briefly described. Next, a broad overview of motivation models and research in terms of their component elements will be presented. The unique motivational opportunities and challenges of instructional simulation will be analyzed. Fourth, practical guidelines for the motivational design of instructional simulations will be offered.

\section{Instructional Simulations}

Instructional simulations provide learners with the opportunity to interact with a representation of some phenomenon or challenge, and in that interaction grow in skill or knowledge. Simulations are used in one of two ways in instruction: either the learner interacts with an existing simulation and develops an understanding of an existing model, or the learner constructs a simulation and personally designs the model, thereby developing a deep level of understanding of the model. The first method, using a pre-existing model, is the more common use of simulation in instruction. An example of this approach is the typical flight simulator where pilots sit in a virtual cockpit and perform the procedures associated with safely flying an actual aircraft. An example of the second method, where the learner constructs the model, is when a science teacher has students use a software program to develop a representation of how volcanoes erupt. The learner researches the process and then builds a simple computer model representing how volcanic activity develops. Learning occurs through the building of the model. Having learners construct models that faithfully represent real-world phenomena facilitates meaningful learning (Jonassen, Howland, Marra, \& Crismond, 2008).

Four Types of Instructional Simulations. There are four main types of instructional simulations and they can be divided into two groups. The first group is simulations that teach about something (Alessi \&
Trollip, 2005), and the two sub-categories of simulations in this first group are physical simulations and iterative simulations. The second group is simulations that teach how to do something, and the two sub-categories in this group are procedural simulations and situational simulations. The four types of simulations (Alessi \& Trollip, 2005, p. 214):

\section{About something simulations \\ Physical \\ Iterative \\ How to do something simulations \\ Procedural \\ Situational}

Physical and Iterative Simulations. A physical simulation is a representation of a physical object or phenomenon with which the learner interacts. A physical simulation represents a physical object and the learner manipulates variables and observes how the physical object reacts. Examples of physical simulations include the action of a rubber ball in bouncing, how oceanic wave systems develop, and how weather systems develop. An iterative system, on the other hand, is similar to a physical simulation, but rather than interacting with the simulation in process, the learner manipulates variables and then runs the entire simulation. In this way, the learner can observe the effects of various parameters on the modeled system by changing the parameters and running the simulation repeatedly. Both of these simulation types help learners understand about things.

Procedural and Situational Simulations. Procedural simulations train a sequence of actions to accomplish an objective. A flight simulator is a good example of a procedural simulation. Given certain conditions, the operator performs certain procedures, and the simulated aircraft is safely or effectively maneuvered. A simulation that is concerned with learning the steps in performing a procedure is a procedural simulation. In contrast, a situational simulation deals with interactions with people or organizations in different situations. A simulation using avatars to teach soldiers to interact with locals in culturally sensitive ways in a war-time scenario is a good example of a situational simulation.

Each of these simulation types presents a unique motivation profile or challenge; an analysis of these unique challenges will follow the description of key motivation principles and practices.

\section{Motivation Theory, Research, and Practice}

Relevant Motivation Theory, Research, and Practice. The body of literature relating to motivation theory and research is extensive, rather than repeat the 
theoretical perspectives and research in detail, the reader is invited to explore the literature and research that is so well represented in the literature. The elements of motivation presented here are drawn from several models and lines of research. These sources include the following:

- The ARCS Motivation Model (Keller, 2009)

- Flow Theory (Czikszentmihalyi, 1990)

- The Taxonomy of Intrinsic Motivation (Malone, 1986)

- The Time Continuum Model (Wlodowski, 2003)

- Motivation System Theory (Ford, 1992)

- Social Learning Theory (Bandura, 1989)

- Arousal Theory (Berlyne, 1971)

- Behaviorism (Buchanan, 1992)

- Self Determination Theory (Deci, 1975)

- Social Factors (Hacker \& Bol, 2004; Palincsar, 1998)

- Identity Leveraging (Erikson, 1980; Lee \& Hoadley, 2000)

- Visual Design (Berlyne, 1970; Csikszentmihalyi \& Robinson, 1990; Tractinsky, Katz, \& Ikar, 2000)

- Structured Story (Parrish, 2009; Schank, 1990)

\section{Component Elements of Motivation}

The extensive literature on learner motivation presents several recurring themes. This section describes the key themes, or component elements of motivation-and briefly describes their theoretical associations. The elements of motivation as represented in learner motivation models and research is presented in Table 1 .

Attention. Attention is gaining and keeping the learners' attention (Keller, 2009). This idea is presented in virtually every theory of learner motivation. It includes concepts such as Berlyne's (1971) arousal of curiosity through novelty or pattern complexity. Flow theory defines itself by this concept of attention, describing a flow experience as one in which the participant's attention is completely absorbed, and time is ignored (Csikszentmihalyi, 1990). Malone (1986) prescribes two primary ways curiosity may be raised: sensory curiosity may be raised by varying stimulus intensity and pattern; and cognitive curiosity may be raised by creating uncertainty. Keller (2009) prescribes all of these methods to enhance learner attention. The goal is to gain the learners' attention and then maintain it.

Relevance. Relevance is connecting the learning with learners' goals and life experiences (Keller, 2009). For a learner to fully engage, the learning experience must have some value in his or her life. Motivation system theory proposes that this goal orientation is the center of human motivation (Ford, 1992), that goals and context are the anchors that organize and provide coherence to behavior. Wlodowski (2003) advocates for the value of this element using the word "need" rather than "relevance." He proposed that the degree to which a given instructional product matches the learner's needs is a key determinant of learner engagement.

Confidence. All of the motivation models reviewed emphasized the importance of learner confidence in determining motivation towards learning. Simply put, if a learner has no confidence that he or she can succeed, effort towards the learning goal will be minimal. Alternatively, if the learner has too much confidence-that learning success may be achieved without effort-minimal effort will be expended (Keller, 2009). Foundational to this notion is Bandura's (1977 ) concept of self-efficacy. Malone (1986), Keller (2009), and Rieber (1996) all emphasize the importance of outcomes being uncertain. There must be a degree of confidence that the learner can succeed, but there also must be a level of uncertainty for optimal learning effort to be expended. This idea of "optimal challenge" is explicitly repeated in several models (Malone, 1986; Csikszentmihalyi, 1990; Riever, 1996; Keller, 2009).

Satisfaction. It is important that learners value the outcome of the instruction (Keller, 2009). For example, if a medical student sees no value in the life or rewards of being a doctor, effort will be restrained. Keller (2009) proposed that this motivational dimension of satisfaction includes both intrinsic and extrinsic motivators. This unique synthesis of Skinner's (1938) behaviorism with Deci and Ryan's (1975) concepts of intrinsic motivation is creative. It is doubtful that either Skinner or Deci and Ryan would agree that intrinsic motivators and extrinsic motivators can effectively be combined in precisely this fashion. But, Deci and Flaste (1995) do describe an interaction of the two that allows for Keller's (2009) formulation. The basic principle is that for learners to energetically engage they must value the outcome of the engagement. Two key prescriptions from the literature are, do not overemphasize extrinsic motivators (this will serve to destroy competing intrinsic motivation), and whenever possible, encourage intrinsic motivation because it is more resilient than extrinsic motivation. Flow. Flow theory is a way of describing the phenomenon where people are caught up in the flow of an activity or game and so enjoy themselves that they lose track of time. Czikszentmihalyi (1990) defined flow as “...the state in which people are so involved in an activity that nothing else seems to matter." Rieber (1996), like Malone (1987), held that the most important element in the creation of a flow experience is optimizing the 


\begin{tabular}{|c|c|c|c|c|c|c|c|c|c|c|c|c|c|}
\hline 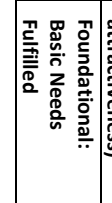 & 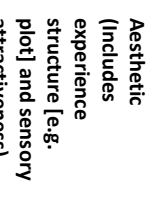 & 兽 & 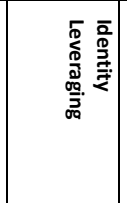 & 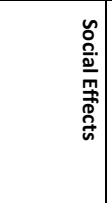 & 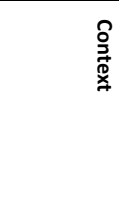 & 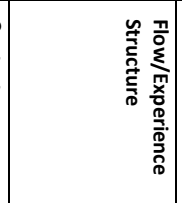 & 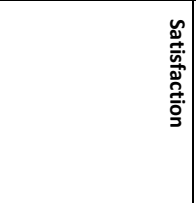 & 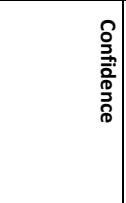 & 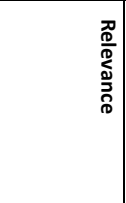 & 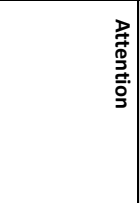 & \multicolumn{2}{|c|}{ 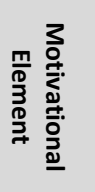 } & \\
\hline 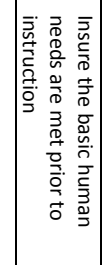 & 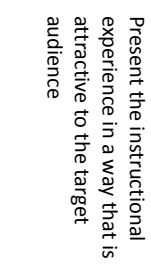 & 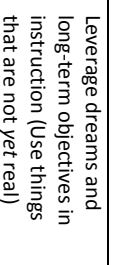 & 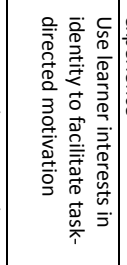 & 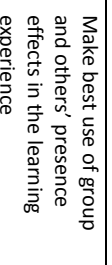 & 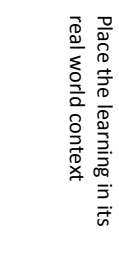 & 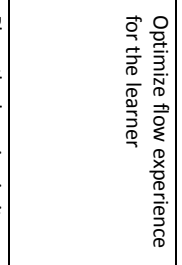 & 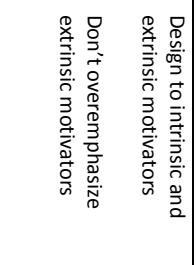 & 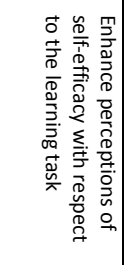 & 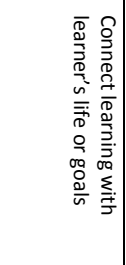 & 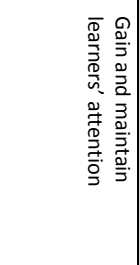 & & 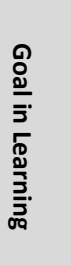 & \\
\hline & 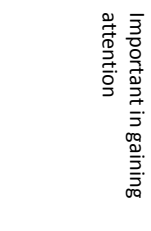 & & & & & 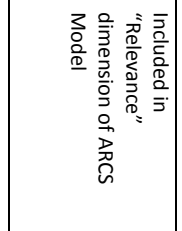 & 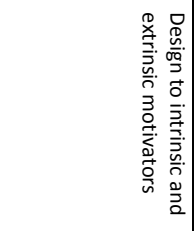 & 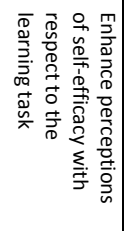 & 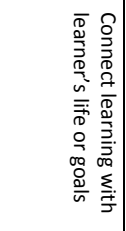 & 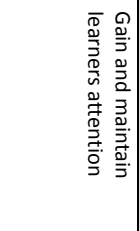 & & 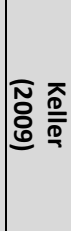 & \\
\hline & 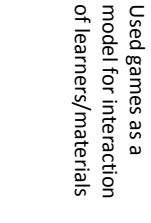 & 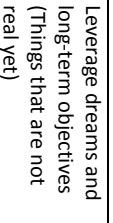 & & & & & 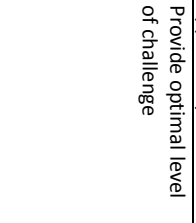 & 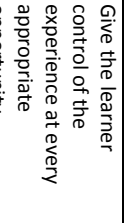 & & 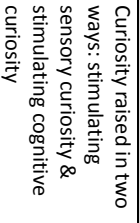 & 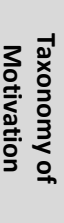 & 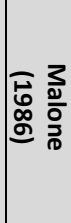 & \\
\hline & 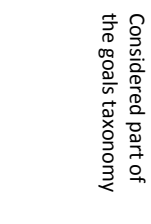 & & & 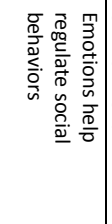 & 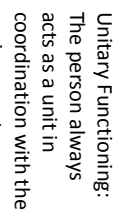 & & 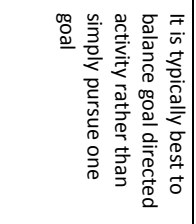 & 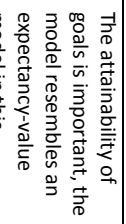 & 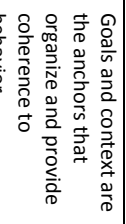 & 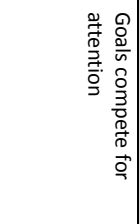 & 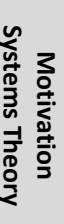 & 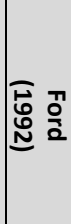 & \\
\hline & 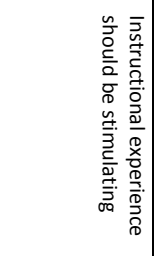 & 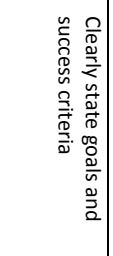 & & & & 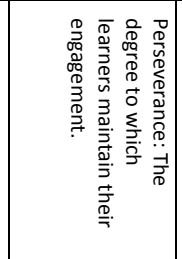 & 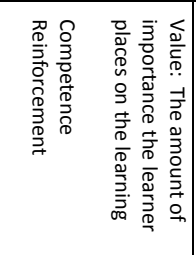 & 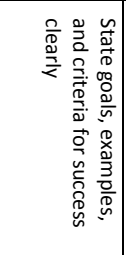 & 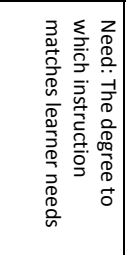 & 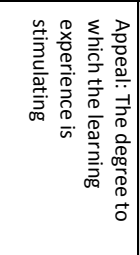 & 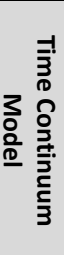 & 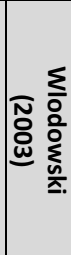 & 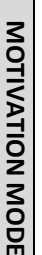 \\
\hline & & & 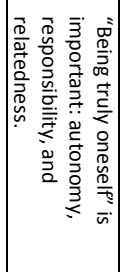 & 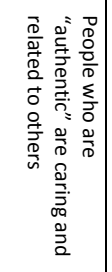 & & & 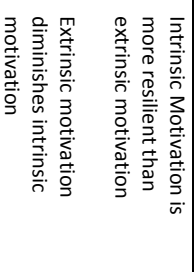 & & & 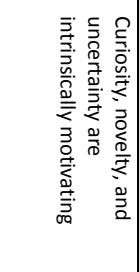 & 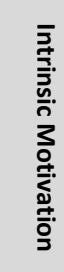 & . & 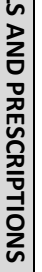 \\
\hline & 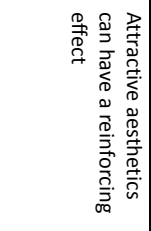 & & & 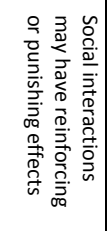 & 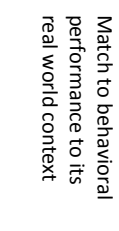 & 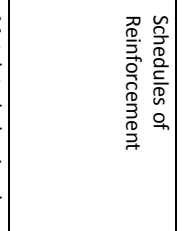 & 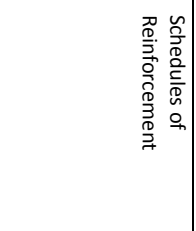 & 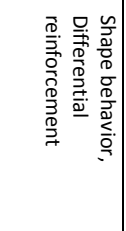 & 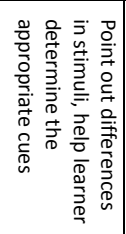 & 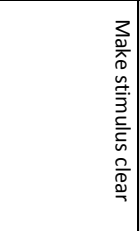 & 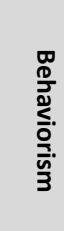 & 焉 & \\
\hline 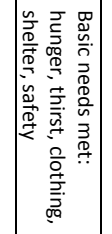 & & & 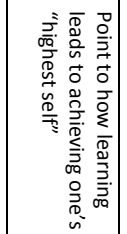 & & & & 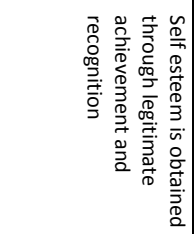 & 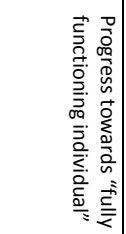 & 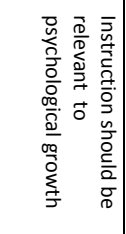 & 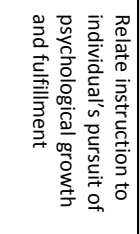 & 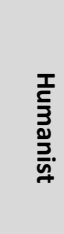 & 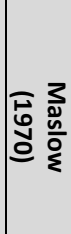 & \\
\hline & 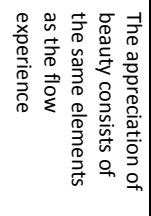 & & & & & 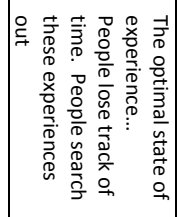 & 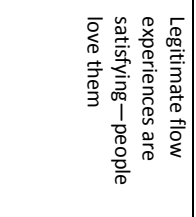 & & 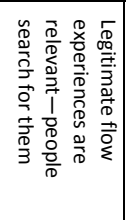 & & & 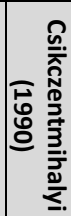 & \\
\hline
\end{tabular}


challenge. This idea is consistent with Keller's ARCS Model as the optimal state for learner confidence (1987). How important is flow in motivational design? People actively seek flow experiences, and will expend energy and resources to find them (Gee, 2008).

Context. Ford (1992) proposed that motivation is the product of the interaction of the person and the context. According to his motivational systems theory, motivation is defined as the pattern of a person's personal goals, personal beliefs, and emotions. A unique perspective this theory brings is the idea of the person-in-context. This is the idea that motivation results from an interaction of the person and the environment. The person will always act as a unit in coordination with the local environment. Motivation is an integrated construct that gives the direction a person is needs, emotional energy to move behavior change towards the direction, and expectancies the person has about progress towards the goal. These three constructs may be represented as a motivation formula:

Personal goals $\mathrm{X}$ Emotion $\mathrm{X}$ Personal Agency beliefs $=$ Motivation

Social Factors. Researchers from various theoretical orientations agree on the basic principle that people are social creatures and social factors influence learning motivation. Social learning theorists, for example, argue that much of what one learns is learned from the example of others (Bandura, 1977; Bruning, Schraw, Norby, \& Ronning, 2004). Cognitive learning theorists maintain that much of learning is devoted to "meaning making" which is essentially a collaborative and social process (Bruning et al., 2004). Interestingly, Hacker and Bol demonstrated that the mere potential presence of others affects individual cognition and behavior (Hacker \& Bol, 2004). One does not have to fully adopt all of these perspectives to grant that social factors powerfully influence learner motivation. Palincsar (1998) held that learning and understanding are inherently social, and that meaning making is a social process; she presents constructivist approaches, such as reciprocal teaching, when students teach to learn, as necessarily social. Furthermore, the research regarding the motivational impact of group association is clear: identifying with a group effects behavioral choice and intensity (Zaccaro \& Dobbins, 1989). Motivational designs of learning experiences should capitalize on group association or group learning effects if possible.

Identity Leveraging. The search for identity is a primary motivator, particularly for adolescents and young adults. Erikson proposed that this search for 'who I am' and 'what I am capable of' in young adults energized behavior and choice (1980). Intentionally incorporating elements that encourage ego identity discovery or exploration (particularly with adolescents and young adults) was discussed as part of the explication of the motivational component of satisfaction above. Since the search for identity is a broadly motivating issue, incorporation of identity facilitating elements would improve the motivational appeal of an instructional simulation, if appropriate to the simulation objective.

Game developers capitalize on this human interest in identity when they create role-play games that allow users to personalize their avatars. Players do not likely expect to find their real-life identities through such features in games, but they are extremely popular and players appear to be fascinated by the options for altering or extending their personalized game identities. Lee and Hoadley (2007) refer to this as "leveraging identity for fun" and observe that game players enjoy the activity. In The World of Warcraft (WoW), players may edit personality and physical features of their personal avatars to match their fantasies or values (Blizzard, 2010). Second-Life (2011), a virtual micro-world, exists almost exclusively for this purpose: providing users with an outlet to play out roles that express hidden or fantasized aspects of their identity. On its home page, Second-Life asks the user the question: "Who will you be?" Second-Life provides robust features for altering a user's avatar's appearance and exploring a wide range of activities and adventures.

Visual Design. That learner persistence leads to improved learning may seem axiomatic, but that the visual design of an instructional simulation may lead to persistence is not. Yet, it appears that attractive visual designs are motivating. Berlyne (1971) described the affective response to aesthetic as energizing and directive to behavior. Czikszentmihalyi and Robinson (1990) proposed that beauty is broadly motivating, observing that the components of aesthetic experience are essentially the same as the components of flow. Not only is visual aesthetic motivating, the motivational challenge rises because today's learners come from cultures saturated with excellent quality visuals. Though preferred styles vary, global cultures are almost universally visual cultures, and becoming more so over time (David \& Gore, 2010; Pink, 2005). Specifically, visual design plays a significant role in user perspectives of credibility and quality of computer applications. Internet users assess the credibility of websites primarily by their visual design (Fogg et al., 2002). Keller (2009) places this visual "excellence" dimension in the "Attention" factor of the ARCS Model, but it is possible that this visual or aesthetic variable is also foundational to learner perceptions of relevance and satisfaction. 


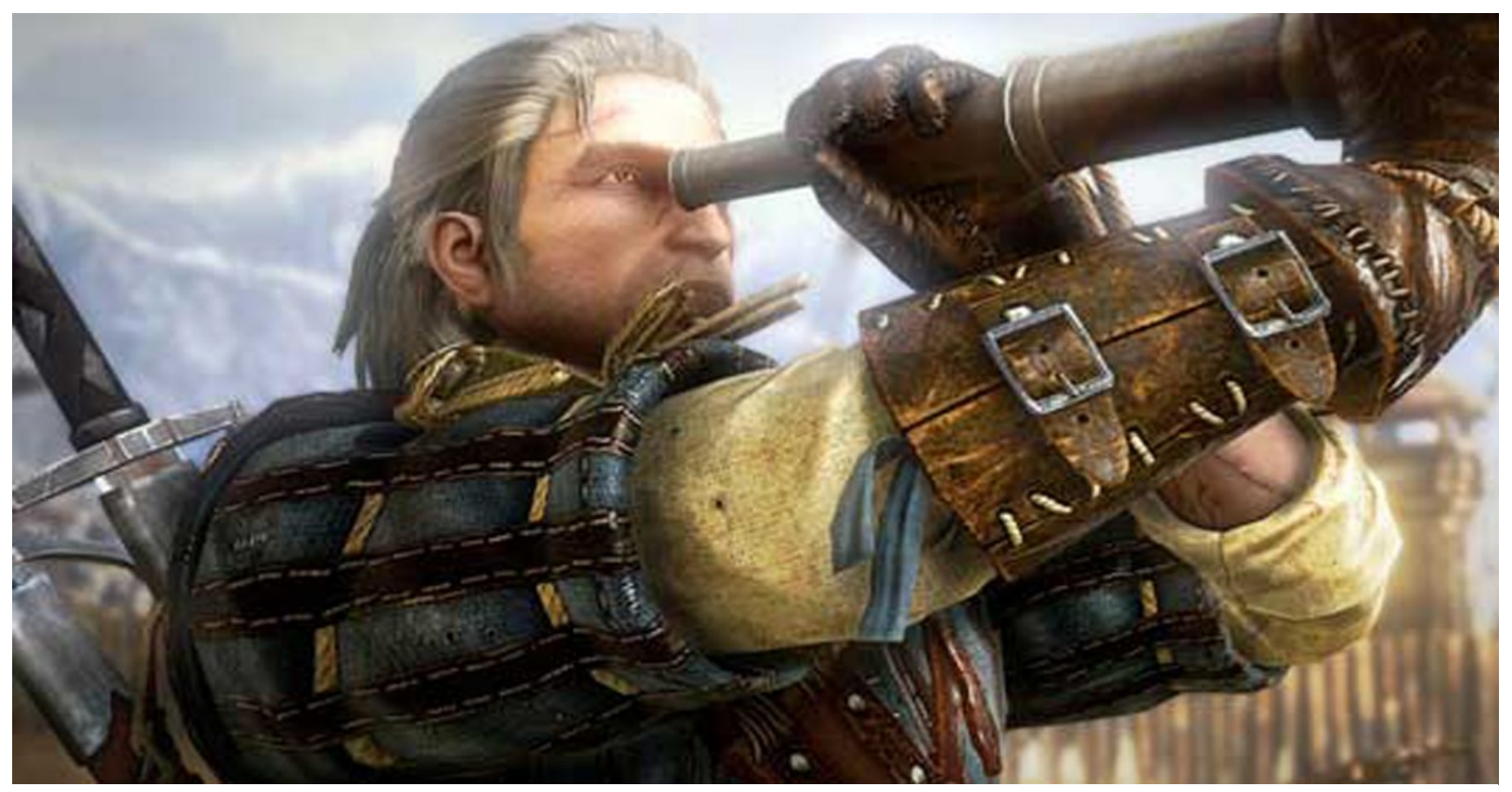

Figure 1. The Witcher: Assasin of Kings, Courtesy of CD Projekt

Game developers often put a great deal of emphasis on visual design. Note the visual detail and attractiveness of the screenshot from the popular Atari ${ }^{\circledR}$ game, The Witcher, pictured in Figure 1. Great care was taken in depicting characters and environments that may be objectively assessed as 'beautiful.'

This game was developed with such visual quality that it became a source of national pride in Poland where it was developed, and Polish Prime Minister Tusk presented a copy of the game to President Barack Obama during the U.S. president's official visit to Poland in May 2011 (Rainier, 2011).

One practical method for designing an attractive visual aesthetic into an instructional product is to use the preferred aesthetic. Beauty may be difficult to define (Berlyne, 1971), but the preferred aesthetic of a target audience may be reliably identified from a group of visual treatments using paired comparisons (Nunnally, 1967). The process is practical: identify candidate visual motifs from popular games or software, select one scene and develop it in each of the candidate motifs, present the treatments to members of the target audience using a paired comparison process (Nunnally, 1967), and utilize the audience's preferred aesthetic in the instructional product.

Structured Story. Screen, theater, and novel writers have made a study of developing story structure patterns that engage users in their products. Parrish (2009) proposed learning experiences should have "beginnings, middles, and endings (i.e., plots) (p. 519)."
He then articulated practical guidelines for building and incorporating story-like tension in learning experiences.

Some claim that stories provide the primary means by which we understand our world: that story provides context, data, and use-cases for how we live (Schank, 1990). The five-act story plot structure, illustrated in Figure 2, is so ingrained in writing practice that its origins are unclear. Recent neuroscience research has shown that certain patterns of plot engage large percentages of audiences in similar ways (Hasson et al., 2008). Game developers, as described above, use stories to create interest in their games. The five-act story structure pictured in Figure 2 is common in novels and cinema as a means for gaining and keeping

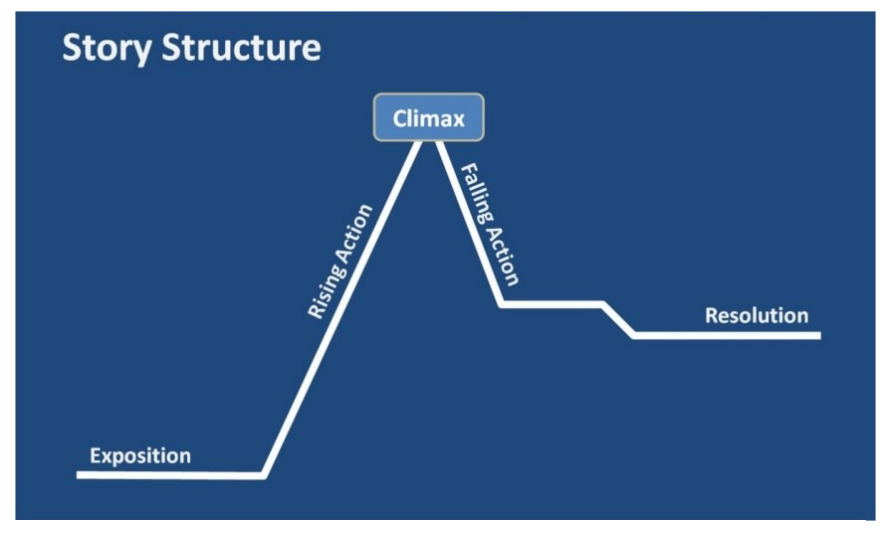

Figure 2. The typical five-act story structure used in literature. 
participant interest. Such patterns could be assessed and used in instructional simulations for the same purpose.

Fantasy and Humor. Schank (1990) proposed the life is understood by story. If life is understood by story, then a related axiom may be that stories engage through humor and fantasy. These are actually two different but complementary concepts. Malone and Lepper (1988) define a fantasy environment as "...one that evokes mental images of physical or social situations not actually present (p. 241)." For an instructional simulation, an example of incorporating fantasy is to allow the learner to operate in a world that is beyond his or her current status. For a student shiphandler, have her be the commanding officer in a scenario. For the student athlete, have him be a professional basketball player in a scenario. The motivational impact of this sort of future-fantasy is powerful. Humor - particularly humor that is relevant to the learning goals - can often make a point with more impact than straight narrative. Further, relevant humor has been effective in improving learning performance (Wazner, Frymier, \& Irwin, 2010).

\section{Motivational Challenges Specific to Instructional Simulations}

Instructional simulations pose unique motivational challenges and opportunities. The most striking opportunity is that instructional simulations are, by definition, active learning. With minimal design forethought, learners may experience a contextualized challenge that approximates real life. This is a significant strength and can serve to offset many of the other challenges in motivational design. Unlike passively listening to lectures, reading a book, or watching a video,

an instructional simulation requires learners to construct responses - often in real-time. This is a significant motivational strength integral to instructional simulations.

The motivational challenges of instructional simulations are, in many ways, related to this strength that the experience is an active learning experience. What can happen is that learners can become lost in the experience, particularly if they are novices to the performance or to the simulation system. This is the most significant motivational challenge to instructional simulations. Care should be taken to guide novice learners through the complexity of the performance or the use of the interface. Otherwise, they may become overwhelmed. The motivational challenges are different for expert performers, novices, and part-task simulations.

Motivational Design for Expert Performers. Expert performers who use a simulation for practice or refresher do not judge the simulation against book learning or classroom experiences, but they evaluate the simulation against the actual task performance (Alessi, 2000). Consider the example of an aircraft pilot taking refresher training in an aircraft simulator. While the pilot may grant some differences between the simulation and the actual flight experience, if the simulation does not include all of the most important performance variables in the task the pilot may reject the simulation completely. It is essential that simulations designed for expert users include all of the salient variables and controls that the performer would use or experience in the actual performance.

This highlights the importance of making intelligent decisions about model and simulation fidelity. Fidelity can never be $100 \%$, but, different simulation contexts require different features. A second useful concept is that model fidelity should be high for the performance being trained, even if the simulation or interface is not a total match to the actual performance. For expert performers, the model should react consistently and accurately, even in simulations that are more simple.

Motivational Design for Novices. In the case of novices, the designer must be aware of the complexity of the task performance and manage cognitive load accordingly. This may be accomplished by developing a model with high fidelity with an interface that presents only the features or controls that are involved in the initial task performance. For example, in a simulation designed to train young ship-handlers the basics of managing wind and current in ship handling, the simulation may present a two-dimensional interface and only the factors relevant to understanding the procedure for maneuvering the ship given the effects of wind and current. The design simulation may leave out the crew, the details of buildings and trees, and other distracting variables.

In addition to managing cognitive load through a simple presentation, novice learners may need both initial simulation orientation and orientation to particularly demanding aspects of the task performance. This may be accomplished prior to the novice's first simulation experience, or as the simulation unfolds. Further, assistance or support may be offered as a preprogrammed feature or as an elective help feature that the learner accesses when needed. Either way, overwhelming a novice performer by either overcomplicating the simulation display or forcing the learner into a too-difficult situation is not conducive to motivation relative to the task.

Having said all that, there is an optimal level of complexity that is energizing to learners, so the designer should not create too simplistic an environment or offer too much background support. The 'Goldilocks 
Principle' applies: graphic presentation complexity and background support need to be "just right." There is an art and science to these design decisions. A good learner analysis is the key to solving the challenge. One technically simple way to address this challenge is to provide learners with choice of difficulty levels, and then design more complexity into higher levels. In this way, simulation complexity may approach real-life complexity while not overwhelming the learner.

Motivational Design for Part-Task Simulations. In some cases, a simulation only addresses a portion of a task, skill, or phenomenon: this is called part-task simulation. This approach is used to train learners component parts of larger skills. The motivational approach is similar to the motivational approach used with novice learners, the under-lying model should respond faithfully, but learners are only presented with the parts of the task that are salient for the component skill. To enhance transfer, it may be advisable to include a few visual elements that will be necessary in performing the subsequent parts of the task, but this is a decision that must be evaluated on a case by case basis. For part-task simulations, then, the key is to present all the relevant stimuli and controls for performance of the identified partial task, and you may decide to add a few visual details that will be incorporated in the subsequent tasks, leaving a path for the next steps in learning the larger task.

\section{Guidelines for the Motivational Design of Instructional Simulations}

The following guidelines are drawn from the literature regarding types of instructional simulations, motivation and motivational design principles from diverse perspectives, and the specific motivational challenges of instructional simulations.

\section{Pre-Simulation Design}

Learner and Content Motivational Analysis

- Conduct a motivational analysis of the target audience using the ARCS Model to structure the effort (Keller, 2009, pp. 197-222).

- Use the ARCS Model to guide materials/ content analysis (Keller, 2009, pp. 222-229).

\section{The Learners' Entrance to the Simulation}

- Provide an intuitive interface (Alessi \& Trollip, 2005).

- Clearly define first steps for user (Alessi \& Trollip, 2005).

- Clearly define the simulation's purposes and desired outcomes early in simulation (Rieber, 1996).

- Specify performance objectives in plain language (Keller, 2009).

\section{Stimulate Curiosity}

- Begin by instilling tension, posing a problem, or pointing out conflicting information (Parrish, 2009; Keller, 2009; Berlyne, 1970; Malone \& Lepper 1988)

- Change task, setting, or context to introduce variation (Keller, 2009).

- $\quad$ Pattern, routine, or established motif can sustain engagement (Parrish, 2009).

- Create sustained suspense by enhancing complication (Parrish, 2009).

\section{Intentionally Structure the Simulation Experience}

- Design the simulation with a beginning, middle, and end; and create resolution or reflection activities for closure (Parrish, 2009).

- Create a short back-story for the simulation scenario (Schank, 1991).

- Place the simulation in the context of an ongoing story structure that brings the activity to a climax and then resolution (Schank, 1991).

- Theme and plot should rise from subject matter but should not be more than subject matter (Parrish, 2009).

- Endings should integrate everything that has occurred up to that point (Parrish, 2009).

- Honor setting or simulation context... Make it fit with and serve objectives (Parrish, 2009).

- Whenever appropriate, model desired performance (Bandura, 1989).

\section{Create Optimal Challenge}

- Design the learning experience to optimize challenge (Malone \& Lepper, 1987). This is accomplished three ways: 1) Use the audience analysis to match learner skill levels, 2) Allow learners to select levels of difficulty, or 3) Program the simulation to detect learner skill level and present challenge at difficulty levels slightly above current level.

- $\quad$ For experts, the simulation must be developed with a high degree of model and simulation fidelity. Experts will judge the simulation against the actual task performance (Alessi \& Trollip, 2005).

- For novices, great care must be taken to manage cognitive load (Sweller, 2002). Develop a very basic beginning to the simulation and appropriately increase difficulty during the process of the simulation. 
- Vary activity and challenge during the simulation (Keller, 2009).

- Incorporate competition carefully. Competition against others may be demotivating to the losers, and Deci and Flaste (1995) demonstrated that it may also decrease intrinsic motivation for the winners.

- Provide opportunities to compete against the computer or against self-determined goals (Malone, 1981).

\section{Provide Feedback and Consequences}

- Provide clear and consistent feedback systems that allow learners to determine whether or not they are reaching the goals on a real-time basis (Rieber, 1996).

- Carefully design consequences to match your objectives. Natural consequences are best, but could overwhelm a novice performer (Deci \& Flaste, 1995).

- Do not present such lavish positive consequences that learners could conclude they are being positively "controlled." Even positive control diminishes intrinsic motivation (Deci \& Flaste, 1995).

- Provide novices (with either the performance or the simulation) with 'Goldilocks Support': Not too much, and not too little. Judging this is art and science. The general rule of thumb here is to allow the performer to perform as much as possible, and support only when necessary (Allessi \& Trollip, 2005).

- Insure that "rules" and behaviors of the simulation are fair, that there is an appropriate opportunity for success and that all participants have equal chance for success (Keller, 2009).

\section{Provide Opportunities for Social Learning}

- Accept that learners as protagonists are fully human (Parrish, 2009).

- Incorporate the stories or examples of likemodels and how they struggled and succeeded (Bandura, 2000).

- Create simulations that may be used in small groups, as teams, or on networks (Zaccaro \& Dobbins, 1989; Palincsar, 1998; Zaccaro \& Dobbins, 1989).

- Use avatars to model performance, offer advice, or perform with the learner (Baylor, 2011).

\section{Leverage Learners' Interests in Identity \\ Encourage Learners to Articulate and \\ Associate with Desired Futures}

- Have learners enter (or select) roles or benefits they see stemming from successful performance of the simulation's learning objectives in real life (Rieber, 1996).

- Provide learners with options to personalize their participation through modifying an avatar (Malone, 1981) (Lee \& Hoadley, 2007).

- Allow learners to choose roles, settings, tools, or tactics for performance (Malone \& Lepper, 1988).

- Create Identity Forming Events and Linkages

- Foster a change or growth in sense of identity; make learning a rite of passage (Parrish, 2009).

- Create opportunities for success in the context of a desired role (Keller, 2009).

- Create opportunities for success in the context of the task performance (Keller, 2009).

- Provide feedback in the context of learner's values or goals (Malone, 1981; Ford, 1990).

\section{Match Learner Goals to Simulation Objectives}

- Have learners select or articulate personal and performance goals relevant to the simulation task (Malone, 1981).

- Have learners select their personal values from a menu, or enter them in a database (Malone, 1981).

- Allow learners to choose tasks that interest them (Malone, 1981).

\section{Present an Engaging Visual Design}

- The interface must be intuitive-especially for new users (David \& Gore, 2010).

- Visual designs may vary in complexity, but they must always have an "apparent excellence." That is, when the target user views the screens, the user must assess them as having quality. Aesthetic judgments are made quickly so the quality of "first views" is important (Zajonc, 1980).

- Every visual design must be attractivesuch are the contemporary demands of our culture (Pink, 2005) (Alessi \& Trollip, 2005).

- Design visuals to the preferences of a sample of your target audience. The elements of high aesthetic are elusive, but preferred aesthetic may be reliably identified (Berlyne, 1971). 


\section{Incorporate Relevant Fantasy and Humor}

- Offer scenarios in which users may assume valued future roles (Malone \& Lepper, 1988).

- Use appropriate and relevant humor to lighten a heavy task or to engage learners (Wazner et al., 2010).

\section{Conclusion}

Instructional simulations are effective in teaching about things and in teaching how to do things (Alessi \& Trollip, 2005). By definition, they require learners to construct responses, and this learner act of constructing a response is to some degree inherently motivating. However, they can also be profoundly confusing to novices, or may miss the degree of realism required by experts. Therefore, motivational analysis and design is an important part of the larger instructional design process for instructional simulations.

Keller's (2009) ARCS Motivation Model is the most comprehensive contemporary motivation model for instructional designers and provides a cohesive framework for analyzing and designing motivation in the instructional environment. Keller's processes for audience and content motivational analysis are effective. The ARCS model alone, as currently defined, is insufficient for the motivational design of instructional simulation. The issue is not the framework, rather, the current explication of the applied details. Therefore, we have drawn from several motivational perspectives in addition to ARCS to construct the conceptual framework for these guidelines. It is a testament to Keller's work that each of the unique motivation elements described here may be appropriately positioned within a dimension of the ARCS framework.

Motivation is a complex process, but motivational goals and objectives may be systematically articulated, and effective tactics and strategies developed. Motivation is the result of a system of factors: attention, relevance, confidence, satisfaction, volition, challenge, identity, social factors, flow, story, and aesthetics that energize learners and encourage them in the learning task. Learning is the result of experience as well as the feedback, correction, and reflection that follows the experience. It is the result of shared meaning making. Learning is an act that a learner undertakes and so motivation is fundamental. Motivation cannot be guaranteed, but it can be systematically encouraged. The guidelines provided here for the motivational design of instructional simulations are offered as a beginning step in the right direction.

\section{References}

Alessi, S. M. (2000). Simulation design for training and assessment. In H. F. O'Neiul, Jr. \& D. H. Andrews (Eds.), Aircrew training and assessment (pp. 199224). Mahwah, NJ: Lawrence Erlbaum Associates.

Alessi, S. M., \& Trollip, S. R. (2005). Multimedia for learning (3rd ed.). Needham Heights, MA: Allyn and Bacon.

Bandura, A. (1977). Self-efficacy: Toward a unifying theory of behavioral change. Pscyhological Review, 84(2), 191-215.

Bandura, A. (1989). Human agency in Social Cognitive Theory. American Psychologist, 44(9), 11741184.

Bandura, A. (2000). Exercise of human agency through collective efficacy. Current Directions in Psychological Science, 9(3), 75-78.

Baylor, A. (2011). The design of motivational agents and avatars. Educational Technology Research and Development, 59(2), 291-300. doi: 10.1007/ s11423-011-9196-3

Berlyne, D. E. (1970). Novelty, complexity, and hedonic value. Perception and Psychophysics, 8 (5A), 279-286.

Berlyne, D. E. (1971). Aesthetics and Psychobiology. New York, NY: Meredith Corporation.

Blumenfield, P. C., Kempler, T. M., \& Krajcik, J. S. (2006). Motivation and cognitive engagement in learning. In K. R. Sawyer (Ed.), The Cambridge Handbook of The Learning Sciences. New York, NY: Cambridge University Press.

Bruning, R. H., Schraw, J., Norby, M. M., \& Ronning, R. R. (2004). Cognitive Psychology and instruction (4th ed.). Upper Saddle River, NJ: Pearson.

Buchanan, R. (1992). Wicked problems in design thinking. Design Issues, 8(2), 5-21.

Csikszentmihalyi, M., \& Robinson, R. E. (1990). The art of seeing: An interpretation of the aesthetic encounter. Los Angeles, CA: Getty Institute for the Arts.

David, A., \& Gore, P. (2010). The impact of design and aesthetics on usability, credibility, and learning in an online environment. Online Journal of Distance Learning Administration, 13(4).

Deci, E. L. (1975). Intrinsic motivation. New York, NY: Plenum Press.

Deci, E. L., \& Flaste, R. (1995). Why we do what we do: Understanding self-motivation. New York, NY: Penguin Books.

Erikson, E., H. (1980). Identity and the life cycle. New York, NY: W.W. Norton and Company.

Fogg, B. J., Soohoo, C., Danielson, D., Marable, L., Stanford, J., \& Tauber, E. R. (2002). How do 
people evaluate a web site's credibility? : Stanford University.

Ford, M. E. (1992). Motivating humans: Goals, emotions, and personal agency beliefs. Newbury Park, CA: Sage Publications.

Gagné, R. M. (1965). The conditions of learning. New York, NY: Holt, Rinehart, and Winston.

Gee, J. P. (2008). The ecology of games: Connecting youth, games, and learning. In K. Salen (Ed.), MacArthur Foundation Series on Digital Media and Learning (pp. 21-40). Cambridge, MA: The MIT Press.

Hacker, D. J., \& Bol, L. (2004). Metacognitive theory: Considering the social influences. In S. Van Etten \& D. McInerny (Eds.), Research on Sociocultural Influences on Motivationa and Learning (Vol. 4, pp. 275-297). Greenwich, CT: Information Age Press.

Hasson, U., Landesman, O., Knappmeyer, B., Vallines, I., Rubin, N., \& Heeger, D. J. (2008). Neurocinematics: The neuroscience of film. Projections, 2(1), 1-26.

Jonassen, D. H. (1988). Designing motivating courseware. In D. H. Jonassen (Ed.), Instructional Designs for Microcomputer Courseware (pp. 397400). Hillsdale, NJ: Lawrence Erlbaum Associates.

Jonassen, D. H., Howland, J., Marra, R. M., \& Crismond, D. (2008). Meaningful learning with technology (3rd ed.). Upper Saddle River, NJ: Pearson Education, Inc.

Keller, J. M. (1987). The systematic process of motivational design. Performance and Instruction, 26(9), 1-8.

Keller, J. M. (2009). Motivational design for learning and performance: The ARCS Model approach. New York, NY: Springer-Verlag.

Keller, J. M., \& Suzuki, K. (1988). Use of the ARCS Motivation Model in courseware design. In D. H. Jonassen (Ed.), Instructional Designs for Microcomputer Courseware (pp. 401-434). Hillsdale, NJ: Lawrence Erlbaum Associates.

Lee, J. J., \& Hoadley, C. M. (2007). Leveraging identity to make learning fun: Possible selves and experiential learning in massively multiplayer online games (MMOGs). Innovate: Journal of Online Education, 3(6).

Malone, T. W., \& Lepper, M. R. (1987). Making learning fun: A taxonomy of intrinsic motivations for learning. In R. E. Snow \& M. J. Farr (Eds.), Aptitude, learning, and instruction: Conative and affective process analysis (Vol. 3, pp. 223-253). Hillsdale, NJ: Lawrence Erlbaum

Malone, T. W., \& Lepper, M. R. (1988). Making learning fun: A taxonomy of intrinsic motivations for learning. In R. E. Snow \& M. J. Farr (Eds.),
Aptitude, learning, and instruction: Vol. III. Cognitive and affective process analyses (pp. 223253). Hillsdale, NJ: Lawrence Erlbaum Associates.

Nunnally, J. (1967). Psychometric theory. New York, NY: McGraw-Hill.

Palincsar, A. S. (1998). Social constructivist perspectives on teaching and learning. Annual Review of Psychology, 49, 345-364.

Parrish, P. E. (2009). Aesthetic principles for instructional design. Educational Technology Research and Development, 57(4), 511-528.

Pink, D. H. (2005). A whole new mind: Why rightbrainers will rule the future. New York, NY: River Head Books.

Rainier. (2011). 'The Witcher 2' given as gift to U.S. President Barack Obama. Retrieved from Worthplaying.Com website: http:// worthplaying.com/article/2011/5/31/news/81621/

Schank, R. (1990). Tell me a story: A new look at real and artificial memory. New York, NY: Charles Scribner \& Sons.

Schunk, D., Pintrich, P. R., \& Meece, J. L. (2002). Motivation in education: theory, research, and applications (3rd ed.). Upper Saddle River, NJ: Pearson.

Second-Life. (2011). Introduction. Retrieved June 2, 2011, from www.secondlife.com

Sweller, J. (2002). Cognitive load theory, learning difficulty, and instructional design. Learning and Instruction, 4(4), 295-312.

The Latin Dictionary (2013, October 7). Movere. Retrieved October 7, 2013 from http:// latindictionary.wikidot.com/verb:movere

Tractinsky, N., Katz, A. S., \& Ikar, D. (2000). What is beautiful is usable. Interacting with Computers, 13, 127-145.

Wazner, M. B., Frymier, A. B., \& Irwin, J. (2010). An explanation of the relationship between instructor humor and student learning: Instructional humor processing theory. Communication Education, 59 (1), 1-18.

Weiner, B. (1992). Human motivation: Metaphors, theories, and research. Newbury Park, CA: Sage.

Zaccaro, S. J., \& Dobbins, G. H. (1989). Contrasting group and organizational commitment: Evidence for differences among multilevel attachments. Journal of Organizational Behavior Management, 10, 267-273.

Zajonc, R. B. (1980). Feeling and thinking: Preferences need no inferences. American Psychologist, 35(2), $151-175$. 
52 www.jaidpub.org · October 2013 - ISSN: 2160-5289 